\title{
The 25th International Symposium on paediatric surgical research
}

\author{
Prem Puri
}

Published online: 9 December 2012

(C) Springer-Verlag Berlin Heidelberg 2012

The 25th International Symposium on paediatric surgical research was held in London, UK from 21st to 22nd September 2012. It was a very successful meeting in which 103 papers related to paediatric surgical research were presented. The Aesculap Prize Session was the highlight of the symposium, with ten excellent papers presented at this session. The Aesculap first prize was awarded to Dr Jan Gosemann from Dublin for his presentation on "Disruption Of PPAR $\gamma$-Signaling Is Accompanied By Increased Activation Of NADPH Oxidase 4 In The Pulmonary Vasculature In Experimental Diaphragmatic Hernia”. The second prize was awarded to Dr Nana Nakazawa from Tokyo for her presentation on "Anorectal Neural Crest Derived Cell Behavior After The Migration Of Vagal Neural Crest Derived Cells Is Surgically Disrupted: Implications For The Etiology Of Hirschsprung's Disease”. The third prize was awarded to Dr Johannes W Duess from Dublin for his presentation on "Rock Inhibitor (Y-27632) Disrupts Somitogenesis In Chick Embryos"

The International Board of Paediatric Surgical Research thanks Professor Agostino Pierro and his team for organising a highly successful meeting in London. 